\title{
Infancia y biopolítica en México contemporáneo. Del amparo de la ley al abandono. Performatividades y paradojas del discurso jurídico de protección a la infancia, en el contexto de la experiencia de una niña ${ }^{1}$
}

DOI: https://doi.org/10.32870/dse.v0i8.305

\section{María Gutiérrez Zúñiga*}

Resumen: Este artículo efectúa una problematización del discurso jurídico de protección a la infancia, así como de las regulaciones y procedimientos a que da lugar particularmente en México, desde la perspectiva de la biopolítica, y específicamente de la teoría de la performatividad discursiva. Para ello, se aborda el "caso" de una niña mexicana que fue sujeta a interdicción por las autoridades gubernamentales, y cuya desaparición — dada a conocer en el año 2009-, ocurrió tras haber estado internada en dos albergues infantiles acreditados oficialmente. Palabras clave: biopolítica, performatividad, leyes, paradojas, infancia.

Abstract: This article attempts to make a problematization of the legal discourse for child protection, as well as regulations and procedures resulting, particularly in Mexico, from the perspective of biopolitics, and specifically from the discursive performativity theory. To do so, it addresses the "case" of a Mexican girl who had been subject to interdiction by government authorities, and whose disappearance - released in 2009- occurred after being forcibly interned during more than three years on two children's shelters officially accredited. Key words: Biopolitics, performativity, laws, paradoxes, childhood.

Los cuerpos no sólo tienden a indicar un mundo que está más allá de ellos mismos; ese movimiento que supera sus propios límites, un movimiento fronterizo en si mismo, parece ser imprescindible para establecer lo que los cuerpos "son".

Judith Butler ${ }^{2}$

¿Qué oposición podría ofrecer el ámbito de los excluidos y abyectos a la hegemonía simbólica que obligara a rearticular radicalmente

*Psicoanalista en relación a la Escuela Lacaniana de Psicoanálisis (ELP). Trabaja como investigadora en el DEEDUC, CUCSH, Universidad de Guadalajara. Correo electrónico: mariaguzu@gmail.com

${ }^{1}$ Este trabajo forma parte del proyecto de investigación a cargo de la autora: Relaciones infancia y parentalidad en México del siglo XXI, el cual está adscrito a la línea de investigación denominada "Sujetos de la educación", al interior del Departamento de Estudios en Educación (DEEDUC), de la Universidad de Guadalajara.

${ }^{2}$ Butler, J. (2002) Cuerpos que importan. Sobre los límites materiales y discursivos del "sexo”. Buenos Aires: Paidós, p. 11. 
aquello que determina qué cuerpos importan, qué estilos de vida se consideran "vida", qué vidas vale la pena proteger, qué vidas vale la pena salvar, qué vidas merecen que se llore su pérdida?

Judith Butler ${ }^{3}$

...infancia ... eterna guardiana de lo que merece sobrevivir.

Giorgio Agamben ${ }^{4}$

\section{Algunos fundamentos en la teoría y primera aproximación al problema}

El presente trabajo, puede decirse que, arranca del amplio horizonte que ha abierto una de las más importantes líneas de investigación de Michel Foucault, en torno a lo que nombró como "biopolítica" (o "administración de la vida"), refiriéndose a las formas de gobierno en Occidente que fueron instauradas a partir del siglo XVII. A través de una serie de estrategias de saber y relaciones de poder, tales formas de gobernar se han enfocado desde entonces y hasta nuestro presente, fundamentalmente a la gestión y al control cada vez más acucioso de los procesos de la vida de la población ${ }^{5}$. De ahí que la concepción de biopolítica represente, desde nuestro punto de vista, una de las más fecundas en el abordaje de la complejidad que plantean las sociedades contemporáneas.

Judith Butler, en su obra de 2002: Cuerpos que importan. Sobre los límites materiales y discursivos del "sexo"', ha avanzado precisamente sobre dicho horizonte, al efectuar un estudio de algunas de las formas y mecanismos que operan a nivel de la relación entre cuerpo y discurso. En efecto, a partir de la dimensión inaugurada por el concepto de "performatividad" del lenguaje $e^{7}, \mathrm{y}$ de lo que Jacques Derrida desarrolló ulteriormente como "fuerza de ley", Butler sostiene que los discursos del poder y de la ciencia poseen un carácter performativo en la producción política de los cuerpos, específicamente en la fabricación social de aquéllos que sí importan, determinando de ese modo las condiciones de realizabilidad o irrealizabilidad de esas vidas humanas, tanto como su destino en la historia. Es así como la filósofa define la performatividad a la que ella se refiere: la práctica reiterativa y referencial, mediante la cual el discurso produce los efectos que nombra a

\footnotetext{
${ }^{3}$ Op. cit., p. 39.

${ }^{4}$ Agamben, G. (2004) Infancia e historia. Argentina: Adriana Hidalgo, p. 195.

${ }^{5}$ Foucault, M. (2007) El nacimiento de la biopolítica. Buenos Aires: Fondo de cultura económica. No obstante, Giorgio Agamben ha hecho una importante problematización al hecho de datar este nacimiento en el siglo XVII, proponiendo que se trata de procesos que ya se prefiguraban sobre todo desde la Antigua Grecia. Cf. Agamben, G. (1998) Homo Sacer: El poder soberano y la nuda vida. Valencia: Pre-textos.

${ }^{6}$ Butler, J. (2002), op. cit.

${ }^{7}$ Concepto original de John Austin, propuesto en su libro: How to do things with words (1962), el cual designa el "hacer" y las "cosas" que se producen a través de las palabras, dando así un valor de acto al hablar mismo, dentro de su respectivo contexto discursivo.

${ }^{8}$ Cf. Derrida, J. Fuerza de ley: El “fundamento místico de la autoridad". 1997. Recuperado en septiembre de 2013, desde http://rua.ua.es/dspace/bitstream/10045/10749/1/doxa11_06.pdf

${ }^{9}$ Op. cit., p. 14.
} 
Infancia y biopolítica en México contemporáneo. Del amparo de la ley al abandono.

nivel de la materialidad ${ }^{10}$ corporal, ocultando y disimulando las convenciones de las que es repetición; es decir, su historicidad. Será de la sedimentación proveniente de dicha función performativa, de la que partirá el carácter y la fuerza de las leyes que logran articular su cumplimiento.

Una de las cuestiones clave en esta formulación de Judith Butler, es que la mencionada producción y determinación de los cuerpos, se realiza específicamente a partir de una operación discursiva de marcaje diferencial de los mismos, en función de cierto elemento que, aun siéndoles — digamos - orgánicamente propio a esos cuerpos, finalmente les es enajenado, en base tanto a la significación con que se le ha revestido al interior del discurso, así como a la taxonomización normalizadora de la que entonces se vuelve objeto. El modo como se inserten los cuerpos en dicha taxonomía, constituirá su "rasgo", el cual les permitirá ser reconocidos, o bien excluidos en la sociedad $^{11}$.

Como lo indica la segunda parte del título de la obra Cuerpos que importan..., el elemento referente y la operación de marcaje discursivo diferencial específico a que aquél da lugar, a los cuales Butler se abocará a estudiar y deconstruir, tienen que ver con la categoría de "sexo". Es así como ella problematiza el alcance restrictivo que, históricamente, ha tenido el paradigma de la heterosexualidad sobre las múltiples vidas humanas, ya que, en función de su tipo de adscripción respecto a los límites planteados por el mencionado paradigma dominante, es que se producen modos de existir considerados "legítimos", reconocidos por "permanecer" en el margen de tal legalidad; pero también se generan otras formas de experiencia que quedan fuera, marginales, excluidas, abyectas ${ }^{12}$, sin contar, —al menos en principio - con otras vías posibles de ser significadas, subjetivadas, y por ende, quedando como inviables en su misma sociedad. Es en ese sentido que la filósofa asegura que la política que regula esas vidas en tanto valiendo o no la pena protegerse - por ejemplo, a través de las legislaciones que determinan agendas gubernamentales en los rubros de la salud, la educación, la seguridad, la defensa de los derechos humanos, en función de cierta definición de cuáles son "las poblaciones vulnerables", etcétera-, ciertamente no pasa por la libertad de elección individual o colectiva, sino que más bien está guiada por los efectos de poder y de normalización, procedentes precisamente de los discursos del poder y del saber que finalmente dan, pues, su materialidad a los cuerpos.

Una primera conjetura del presente artículo, tiene que ver con sostener que esta formulación de Butler concierne precisa y directamente también a otras "zonas" de experiencia de lo humano que, como aquella tocante al sujeto sexuado, — e incluso en una intrincada relación con éstatranscurren también a través del tenso cruce constantemente producido entre lo corporal y lo dis-

${ }^{10}$ En este texto, Butler hace una diferencia entre lo material y la materialidad. Lo material tiene que ver con el carácter más fijo del cuerpo, en relación a sus contornos y movimientos; y la materialidad es el efecto más productivo del poder. Cf. Op. cit.

${ }^{11}$ En tiempos del nazismo, la banda con la estrella símbolo de los judíos, aparece como uno de los ejemplos más claros y brutales de estos mecanismos de discriminación en base al propio origen, a la pertenencia a una raza y una religión.

${ }^{12}$ Butler remite a la raíz latina del término: ab-jectio, arrojar fuera, desechar, excluir. Cf. Op. cit. 
cursivo. Nos referimos a la experiencia de infancia en relación con las leyes que se pronuncian por su protección. En efecto, de manera muy cercana a lo que la citada autora ha postulado acerca de la categoría de "sexo", la referente a "infancia" es asimismo un terreno conflictivo en cuanto que tiene una historia cubierta por la figura del sitio, o la superficie de inscripción ${ }^{13}$, por la figura del "hecho "biológico" que, en el caso específico del sujeto de la niñez está asociado a su condición intrínseca de neotenia o prematurez embriológica, pero cuya experiencia adquiere, no obstante, su estatuto humano al ser apropiada por la cultura; es decir, traspasada por el lenguaje y significada ${ }^{14}$. De esta manera, podría pensarse que, relativamente a la par de la "historia de la sexualidad" propuesta por Michel Foucault, - $-\mathrm{y}$, como ya se mencionó, datada por él sobre todo a partir de los últimos tres siglos en Occidente - ${ }^{15}$ se llevaría a cabo también una "historia de infancia", en el sentido de la emergencia y exuberancia de producción discursiva acerca del niño, generada desde los poderes y los saberes. A través de esa historia, se conformaría también la infancia precisamente como ese "terreno conflictivo" o "superficie de inscripción" — esa atrayente "página en blanco", de acuerdo a la metáfora con que se solía caracterizar a la niñez-, volviéndola objeto de sendas diferenciaciones, normalizaciones y regulaciones.

En efecto, al hacer avanzar las implicaciones del planteamiento de Butler, y colocando a la par nuestra anterior propuesta, resulta fundamental tomar nota y puntualizar que, tanto en el campo de la experiencia sexual, como también en el de la experiencia infantil, lo que, en función de estos procesos históricos de producción discursiva se decanta, y queda del costado de lo que es rechazado y excluido en tanto que "anormal", es entonces lo que — citando nuevamente a la filósofa— llega a conformar...

aquellas zonas "invisibles", "inhabitables" de la vida social que, sin embargo, están densamente pobladas por quienes no gozan de la jerarquía de los sujetos, pero cuya condición de vivir bajo el signo de lo "invivible" es necesaria para circunscribir la esfera de los sujetos..., constituirá ese sitio de identificaciones temidas contra las cuales... (el sujeto socialmente reconocido se instalará) $)^{16}$.

${ }^{13}$ Op. cit., p. 22.

${ }^{14}$ Vale la pena citar aquí un importante planteamiento de G. Agamben en Infancia e historia (op. cit.), en relación a la infancia, donde no se la remite meramente a una época cronológica y evolutiva, sino a una posición estructural o experiencia de lo humano, en relación a la posibilidad de su traducción en lenguaje y, en ese sentido, a su historización. En lo que se refiere a la conjetura recién expuesta sobre la cercanía entre las categorías del "sexo" y la "infancia", a partir de que ambas son tocadas radical y analíticamente por lo que Butler plantea, quepa añadir que están efectivamente emparentadas, entretejidas -al menos para la humanidad que conocemos hasta ahora- alrededor de un núcleo enigmático: la cuestión del origen y la reproducción.

${ }^{15}$ Cf. Foucault, M. (2008) Historia de la sexualidad. (Vols. I y II). Buenos Aires: Siglo XXI. Al respecto de la localización temporal del nacimiento de la biopolítica, el cual daría pie a la historia de la sexualidad, -pero también a la historia de la infancia, de acuerdo a lo que se plantea enseguida, dentro del cuerpo del texto-, valdría la pena insistir en reconsiderar la problematización efectuada por G. Agamben, a la cual ya se hizo referencia en la nota al pie 6, en este mismo trabajo.

${ }^{16}$ Op. cit., p. 20. 
Infancia y biopolítica en México contemporáneo. Del amparo de la ley al abandono.

Estas zonas de "inhabitable invisibilidad" no permanecen completamente ocultas, inmóviles o silenciosas. Si bien es cierto que lo excluido se plantea como confirmación de la norma, a partir de una tesis psicoanalítica freudo-lacaniana ${ }^{17}$, Butler añade: "Lo que se rechaza en el orden simbólico reaparece en lo real..." Es decir, lo que no tiene lugar en el discurso, aparece, se muestra, se revela de alguna manera en el contexto social en cuestión, como una forma de exigencia de su reconocimiento. Se trata — nada menos que - del punto de inflexión del planteamiento político de la filósofa: la exclusión performativa ${ }^{18}$ de ciertos cuerpos al interior de una sociedad ${ }^{19}$, no transcurre sin consecuencias y efectos que cuestionan, problematizan, e incluso tienen un potencial destructivo de la legitimidad discursiva, que da origen a tal exclusión, sobre todo cuando ésta ha tenido un carácter francamente violento. Es decir, aquello humano rechazado, insiste y reaparece de diversos modos que, desde una postura crítica como la que Judith Butler sostiene, los estudiosos podríamos retomar ya no más desde el ángulo que las plantea, cual meras manifestaciones de transgresión o de anormalidad, sino sobre todo desde su faz que exige interrogar y deconstruir la mencionada legitimidad discursiva dominante.

Los elementos teórico-analíticos de la propuesta butleriana, esquemáticamente expuestos hasta aquí, tienen una especial pertinencia en el abordaje de la cuestión de la niñez en México, al advertirse que, al igual que en la gran mayoría de las sociedades de masas contemporáneas en todo el mundo, una de las tendencias políticas más fuertes a nivel de los gobiernos, en lo que toca a la preocupación por el "bienestar y desarrollo" de su población infantil, es la de buscar proteger y garantizar tales metas, fundamentalmente a partir de la plataforma legislativa, de la creación de más y mejor elaboradas leyes y regulaciones a favor de este segmento poblacional. De la mano con dicha tendencia, irá la correspondiente prescripción de ciertos modelos de "adecuación", "normalidad" y "funcionalidad" de la experiencia de la niñez — y de los concomitantes entornos familiares, escolares y de sus comunidades en general—, que estarán prescriptos por disciplinas científicas y especializadas que abanderan el "bien del niño", anticipándolo y universalizándolo². Ciertamente, a través de canales como la educación formal, los medios de comunicación, la opinión de los expertos, etcétera, dichos modelos han venido permeando gradualmente la vida social. Sin embargo, en principio, llama la atención cómo algo de lo que sucede a través de estos procesos biopolíticos, es

${ }^{17}$ Efectivamente, la tesis será planteada inicialmente por Freud, pero Lacan (1955-1956), a partir de su postulación del trinario Real, Simbólico e Imaginario, la sostendrá -nada menos que- como mecanismo propio de la alucinación, dentro del campo

de las psicosis. Cf. Seminario III: Las estructuras freudianas en las psicosis (1984). Buenos Aires: Paidós. Vale la pena tomar nota de las implicaciones doctrinarias y clínicas que plantea para el psicoanálisis esta "coincidencia" localizada por Butler, la cual logra esbozar cierta línea de continuidad entre las polaridades del "afuera" y el "adentro", lo "subjetivo" y lo "objetivo", lo "individual" y lo "social".

${ }^{18}$ De acuerdo a lo que se expuso antes, se trata de los efectos materiales (en los cuerpos y en las vidas afectados) de la exclusión perpetrada por los discursos normalizantes.

${ }^{19}$ A partir de su forma de sexuación, -y añadiremos-, de ciertas maneras de vivir la infancia.

${ }^{20}$ ¿Hasta qué punto tal anticipación y universalización son posibles?, o, ¿en qué otra medida se trata de una cuestión que únicamente la trayectoria singular de vida de cada menor permite trazar, y sólo a posteriori? 
el perfilamiento de una figura jurídica del niño y del menor de edad que presuntamente "necesita" ser revestida cada vez más de múltiples y más amplios derechos que lo protejan ${ }^{21}$, sin que, evidentemente, se dé cuenta de la correspondiente implicación performativa a nivel de:

1) El carácter no "natural", construido o de convención histórica presente en el conjunto de premisas que articulan dichas medidas jurídicas; el modo como ellas producen precisamente, ese objeto sobre el cual legislan: el "deber ser” en la vida de un niño dentro de su propio entorno.

2) Las consecuencias y dificultades que paradójicamente podrían derivarse de esas leyes — y de hecho, se están derivando, de acuerdo a lo que este texto planteará páginas más adelante- sobre cada una de las vidas concretas de los sujetos que quedan involucrados.

Ante la posibilidad, pues, de estudiar y problematizar el discurso jurídico en torno a la niñez, la primera vertiente que se abre - y que, por nuestra parte interesa seguir — es localizada a partir de la observación, en torno a cómo la antes descrita apuesta lanzada sobre la vía legislativa, pareciera operar como si se tratara del "único" camino civilizatorio al que es posible apelar, en lo que toca a la agenda política de amparo a la población infantil, -especialmente aquélla que se considera más "vulnerable". Este camino presupondría además, que todas las otras formas de protección a la infancia, incluidas aquellas formas "domésticas", cotidianas que, de facto se ejercen y tienen vigencia por parte de los grupos familiares sobre todo, - pero también de cierto ámbito de relaciones humanas más o menos espontáneas que se producen en el contexto escolar- tendrían que organizarse y efectuarse cual si súbita y fundamentalmente tuvieran que responder y guiarse por el derecho que tendría el niño a contar con ellas.

Esta especie de arrogación por parte de la ley, ciertamente contrasta frente a la constatación histórica de esa ancestral labor ${ }^{22}$, a favor del cuidado de la vida nueva, que se reproducía y crecía al interior de los hogares, dando lugar a las heterogéneas y cambiantes prácticas de crianza y educación de los niños, que han venido siendo llevadas a cabo por "los mayores", principalmente en lo que se ha denominado "la vida privada" ${ }^{23}$. Si bien, de diversos modos, esa labor y sus prácticas han

${ }^{21}$ No deja de inquietar lo que de ello se desprende y vislumbra a nivel del escenario social, haciéndonos preguntar: ¿De qué clase de sociedad se está tratando, cuando hay que defender y proteger tanto legalmente a los niños? Y sí, los niveles de violencia que aquejan a la sociedad mexicana, en donde los menores quedan afectados, incluso de trágicas formas, apuntan a corroborar y justificar dicha aprehensión.

22 Retomando el término de Hannah Arendt para designar el conjunto de tales prácticas, diferenciadas de aquellas relativas al “trabajo" y de la "acción". Arendt, H. (2005). La condición humana. Buenos Aires: Paidós.

${ }^{23} \mathrm{Al}$ respecto, es muy interesante lo que Giorgio Agamben nos revela en cuanto a que el concepto de "vida privada" proviene de los antiguos griegos, quienes consideraban que aquello que palpitaba y se desarrollaba al margen de la acción de la polis y en la domesticidad de los hogares - donde habitaban de forma más permanente sobre todo las mujeres, los niños, los esclavos-, era la $z o e ́$, es decir, la vida privada de cualificación. En cambio, bios era precisamente la vida cualificada que se cultivaba en la ciudad. Sin duda, se trataba de un lenguaje y de una visión sostenidos desde el lugar del "amo". Agamben, G. Homo sacer: El poder soberano y la vida nuda (2010). Valencia: Pre-textos. 
Infancia y biopolítica en México contemporáneo. Del amparo de la ley al abandono.

estado siempre permeadas por tradiciones y costumbres antecesoras, que han sido transmitidas y reinventadas en el tiempo y a través de la bisagra generacional ${ }^{24}$, es importante admitir que aquello que las ha movido, si bien habrá estado permanentemente traspasado por la ley de la polis, al mismo tiempo es, y ha sido, irreductible a ésta. Eso "irreductible" nos remite directamente al campo del amor, el erotismo y el cuerpo, el cual funge como motor ${ }^{25} \mathrm{y}$ da su consistencia a las relaciones dentro de los grupos familiares; no obstante, haga a la vez que dichas relaciones transcurran en medio de sucesivos tropiezos, revueltas pasionales y vicisitudes subjetivas, y que avancen siempre claudicantemente, "a tientas", acertando y errando un tanto azarosamente, respecto a sus viejos encargos culturales, en torno a la formación de los más jóvenes bajo su tutela ${ }^{26}$.

Entonces, lo que habría que reconocer en principio, es que las legislaciones a favor de la infancia - ese invento relativamente reciente en la historia de la humanidad-, a partir de su edicto mismo no se articulan a, sino que se imponen, literalmente pasan por encima de ese campo subjetivo en el que se entraman las relaciones padres-niños, adultos-menores dentro de una sociedad. A pesar de que, a partir de que esa "lógica" que anima este campo nodal, ha sido la que, bien o mal, desde años inmemoriales ha hecho posible la supervivencia y las innumerables trayectorias en el mundo humano de, al menos una parte de la población de los infantes nacidos ${ }^{27}$, el discurso jurídico lo omite, lo eclipsa bajo la sombra de su égida. Por tanto, precisamente habría que interrogarse acerca de las consecuencias y efectos materiales del escamoteo legal de ese campo. Expliquemos a qué se está aludiendo.

En primer lugar, una vez que el "buen trato al niño" ha sido discursivamente propuesto y convertido en derecho de este último, ese trato "deseable" deja de ser uno de los resultados posibles de la relación misma del niño con las redes de parentesco que — se supone — están al cuidado de él, un producto de la densidad particular que conforma dicha relación y de los movimientos que ocurren

${ }^{24}$ Así como expuestas a los rápidos movimientos socioculturales globales -entre los que se cuenta, justamente, el avance de la biopolítica y la sofisticación de los sistemas jurídicos- que, sobre todo en nuestra época han venido transformado radicalmente a las familias y a las comunidades urbanas y rurales.

${ }^{25}$ En el sentido fuerte de lo que "causa" la subjetividad, de acuerdo al planteamiento de Jacques Lacan respecto al llamado “objeto $a$ ". Se trata de un "motor" que se produce en el contorno del cruce cuerpo-lenguaje; es decir, en el vacío que genera el entrelazamiento de los registros correspondientes al real, simbólico e imaginario. Por tanto, en lo que toca específicamente a la puesta en operación de las relaciones familiares, puede decirse que lo que las mueve y las anima, no cuenta con un sustento de entrada, instintivo, filogenético, (como ocurriría generalmente en los animales), tampoco la omnipresencia per se de la cultura, sino que se conforma a partir de ciertas condiciones o modos del mencionado entrelazamiento de esos registros constituyentes de la realidad humana, en los que están precisamente incluidos los sustratos material y cultural. Cf. Lacan, J. (1974-1975). Seminario xxir: Real, Simbólico e Imaginario. Traducción del seminario oral en francés, por R. E. Rodríguez Ponte. Buenos Aires: Escuela Freudiana de Buenos Aires. (Versión no publicada).

${ }^{26}$ Por cierto que habrá de reconocerse que este carácter "fallido", según será planteado en las páginas siguientes, no le es exclusivo a tal quehacer propio de la vida privada familiar, sino que es más que compartido, de acuerdo a lo que propuso Sigmund Freud respecto a "las tres profesiones imposibles: educar, gobernar y psicoanalizar". Cf. Freud, S. (1937). Análisis terminable e interminable. Obras Completas. Buenos Aires: Amorrortu, t. XXIII.

${ }^{27} \mathrm{Si}$ bien se sabe que en otros muchos casos, ha sido lo que las ha segado o imposibilitado. 
en ella. De esa manera, la protección del menor deja de ser "la cosa" que, por principio concierne precisamente a cada una de estas redes, volviéndose paulatinamente una cuestión ordenada desde la polis. Es así como discursivamente se le sustrae a los entramados familiares, nada menos que de su móvil y de su referencia ${ }^{28}$.

Un segundo efecto del citado escamoteo, ciertamente tiene un carácter paradójico, pues a la par que aquella modesta labor de crianza dentro de los hogares ha cobrado importancia jurídica, así como también una progresiva y particular "visibilidad" para las legislaciones, —que habrían sido impensables antes del siglo XVIII en Occidente-, una vez auto-decretado como su nueva referencia, el derecho que protege a la niñez toma como su objeto al mencionado hacer de las familias; sí, pero, con fines de control y escrutinio, poniéndolo bajo la lente y los filtros de la diferenciación normalizadora y excluyente, por lo que su interés aparece sobre todo cuando existe el indicio o la confirmación de que se ha cometido una transgresión. Como se podrá advertir, se trata de uno de los efectos "persecutorios" de estructura de toda ley: ella únicamente puede mirar sus objetos desde el ángulo de lo que condena, de lo que, desde su parámetro se desvía o cae en falta².

Finalmente, una tercera consecuencia a enunciar en este mismo sentido y, por cierto, muy vinculada a la anterior, la cual será muestra muy significativa de cómo trasciende de manera material y corporal esa sustracción operada por la ley, —repetimos, pasando por encima de la relación de los miembros mayores del grupo familiar y el niño- es que las voces de todos ellos, en adelante serán políticamente relevantes, audibles, incluso convocadas, pero solamente bajo las circunstancias precisas del emprendimiento de una queja o de un juicio. Se escucharán en lo que dicen, en lo que saben, pero en su carácter y valor de testimonios para los expertos, como "pruebas" en función del sustento del "caso" que, en lo adelante constituyen para la autoridad judicial a cargo.

Un punto importante a añadir aquí, es que tal omisión en que la ley misma se funda, y que ella efectúa a su vez — es decir, tanto el modo como hace de lado la relación familiar para poder sostener su edicto, como lo que proscribe a través de la aplicación de los procedimientos y medidas impuestas a quienes la violan — ${ }^{30}$, hará resonancia y se reproducirá como tal, aún más allá de los sujetos indiciados cuyo proceder con respecto al menor, se ha juzgado que está fracasando en cuanto a su adecuación a los nuevos códigos jurídicos establecidos. Es decir, el no reconocimiento de lo que constituye un plano absolutamente trascendental de la cuestión, pasa y pesa también so-

${ }^{28}$ Cabría preguntarse al respecto: ¿En qué medida esa nueva legalidad a la que queda sujetado el ya multicitado hacer de las familias hacia su descendencia, ha venido infiltrando y resignificando éste, por no decir que cooptándolo? A nivel de las prácticas cotidianas en que se concretiza tal labor, ¿cuáles están siendo las consecuencias en la experiencia colectiva, toda vez que discursivamente son introducidas, tomadas por una racionalidad biopolítica, mutándolas -acaso hipotecándolas-en deberes y obligaciones a cumplir, pero esta vez bajo su nuevo estatuto jurídico de mandatos de Estado? Se trata de cuestiones que, si bien inciden en la experiencia que se aborda en este artículo, no serán abordadas directamente aquí.

29 De aquí que habría que estar bien advertidos frente a las iniciativas y reformas de ley que se plantean como "la solución" a graves problemas sociales, ya que entrar en el "cerco del ojo" de la ley no ocurre sin pagar el costo de la reducción descrita.

30 De acuerdo a lo que se verá con claridad, a partir de la experiencia de la niña Ilse Michel Curiel, a abordadas en las páginas que siguen. 
Infancia y biopolítica en México contemporáneo. Del amparo de la ley al abandono.

bre los cuerpos y las vidas de los niños que, precisamente en función de la legislación protectora, se dictamina, por ejemplo, que han sido víctimas de abandono, mal-trato o ab-uso ${ }^{31}$.

Efectivamente, el proceso de sanción y penalización de lo que se ha dado en llamar como "malas prácticas" en el contexto de la crianza y la educación, así como de las familias que — se presume - las llevan a cabo, del modo como se plantea para las legislaciones protectoras de la infancia, genera a nivel discursivo y de su praxis, un tajante extrañamiento ${ }^{32}$ de ese ámbito relacional crucial que, — más allá de los criterios y peritajes psicopatologizantes de los especialistas —, para su fortuna o desgracia, es constitutivo de los niños y niñas, de sus cuerpos y de la experiencia de sí.

Lo anterior no se formula aquí desde un interés exclusivamente "teórico" sobre la cuestión, sino también a partir de las posibles implicaciones que esto tiene en el campo de las vidas concretas de niños y niñas que, por motivos diversos, han tenido y tendrán que pasar por ciertos "caminos" que marca la ley que se propone a su favor, al ser motivo de un proceso judicial.

Hace ya más de un siglo que justamente se quitó sustento a la suposición de que el sujeto de la infancia era "una página en blanco"33. Desde su nacimiento, su cuerpo es como una superficie topológica carnal que plantea torsiones, pliegues y agujeros, que a su vez mantienen una constante y dinámica relación espacial interior-exterior, que entrelaza, de entrada, elementos reales, simbólicos e imaginarios. Así, el "alma" que le permite palpitar, sostenerse, existir como cuerpo humano (más allá de cualquier parámetro de "normalidad), es el nudo complejo o amasijo móvil que él mismo materialmente conforma, a través del curso de la historia de sus intercambios y lazos con los otros;

${ }^{31}$ Es significativo el hallazgo compartido por diversos profesionales que trabajan con menores, en cuanto a la frecuencia con que estas tres "malas prácticas" en relación a los niños y adolescentes, aparecen juntas en la experiencia de muchos de ellos. De algún modo, las tres se implican unas con otras, y tocan frontalmente la problemática del "goce" en la vida subjetiva, abordada extensamente en la obra de Lacan, así como vinculada nada menos que a la cuestión del plusvalor en la operación del concepto marxista de capital. (Ver al respecto el artículo de Sous, J. L. Escroquerie: ¿Es superfluo que el capitalista ríe? En: Artefactos 2.Revista de la Escuela Lacaniana de Psicoanálisis. México: Ortega y Ortiz editores. Otoño 2011). Por cierto que, vale la pena hacer notar cómo el propio verbo "abusar", contiene dos elementos del latín: $a b$, que remite a la idea de alejamiento o repulsión, pero tambiéna la de superación o exceso; y por otra parte, usare, "valerse de" o "servirse de". Si bien, el término asimismo latino: abusus tenía más el sentido de "burlar" y "perjudicar", actualmente predomina: "usar en exceso". El interés de esta nota -no obstante a que alude a problemas que bordean y desbordan el objetivo de este artículo- radica en que permite mantener a la vista de nuestra consideración, la complejidad subjetiva que entrama las relaciones operantes entre padres-hijos, adultos-niños, entre las que se incluye también, por supuesto, la situación que vincula maestro y alumno.

32 De manera similar a como opera el modelo dominante de la medicina y su concepción de "enfermedad a curar", lo que significa generalmente "combatir, atacar, extirpar, hacer desaparecer el mal que aqueja al enfermo".

${ }^{33}$ Nos referimos a uno de los principales hallazgos del fundador del psicoanálisis, Sigmund Freud. Sin embargo, por desgracia, la teoría freudiana se ha convertido en uno de los pilares de la psicopatologización y la normalización, que son a su vez, instrumentos de la biopolítica que se ejerce e impone particularmente sobre la infancia. 
lazos hechos con los hilos de las palabras y los actos revestidos de erotismo, que le "han dicho" al niño lo que él significa para los suyos, en el "contexto" de la sociedad y la cultura en que habita ${ }^{34}$.

Entonces, se podría interrogar: ¿cómo es que una razón de Estado se plantea otorgarle y asegurarle una vida cualificada al niño, pasando por encima, y en muchos casos proscribiendo de forma totalizadora esa condición relacional de su experiencia (tramada entre ellos y su respectiva familia, considerada generalmente "desintegrada y/o disfuncional"), que forma parte de lo que ellos son, de lo que - quiérase o no- les pertenece y a lo que pertenecen? ${ }^{35}$ ¿Cuáles son las consecuencias y metamorfosis que se producen a nivel de la materialidad o inteligibilidad política del niño y su cuerpo - una vez que es objeto de la intervención gubernamental para su protección, respecto del tipo de trato que recibe por parte de su propio grupo familiar-, así como sobre su vida, una vez que se parte de que ese nudo de relaciones constitutivas le puede ser jurídicamente sustraído, y se procede materialmente al respecto, a la manera de una "extracción quirúrgica"? En este último caso, importa especialmente estudiar entonces: ¿“de quién” pasan a ser esos menores de edad, cuando es claro que la pertenencia a un cierto tejido de parentesco (consanguíneo o por adopción), su "importarle a alguien", — esa liga del orden del campo subjetivo, del amor y del odio, que se ha dicho articula las relaciones familiares (entre otras) - significa la única posibilidad real de que su vida valga la pena cuidarse y efectivamente se cuide? ¿Es el Estado y sus instituciones -regidos por la ley- en los hechos capaz de sostener la sustitución de dicha "tenencia-autoridad" sobre los niños?

Abordaremos estas cuestiones a través de lo que dice el despliegue de la experiencia de una niña mexicana, a partir del registro efectuado de algunas de sus huellas, las cuales han sido dadas a conocer públicamente por los medios de comunicación, a manera de noticias acerca de un "caso". Previamente, expondremos una breve revisión de la perspectiva del discurso oficial sobre el tema.

\section{El decir de un jurista: "la protección a la infancia es prioridad para el sistema jurídico en México contemporáneo"}

En su investigación sobre la legislación mexicana, a propósito del tema de la niñez, el abogado César Sotomayor ${ }^{36}$ reconoce que la figura del niño con derechos en la sociedad, tiene una data bastante reciente, siendo la infancia un rubro del que las regulaciones constitucionales en el mundo vienen a ocuparse bastante tarde en el curso de la historia, dado que tradicionalmente se había pensado al

\footnotetext{
${ }^{34} \mathrm{El}$ anterior planteamiento se sustenta sobre todo en elementos doctrinarios, resultado de la experiencia de Jacques Lacan, que han sido evidentemente considerados también en el citado trabajo de Butler. Cf. Lacan, J. Seminario XXII: Real, Simbólico e Imaginario (1974-1975). Op. cit.

${ }^{35}$ Es decir, que tal condena no redimiría, antes bien al contrario, podría contribuir a proscribir aún con mayor fuerza, ciertos ámbitos de la experiencia de los niños, alejándolos de la posibilidad de significarse, historizarse en la sociedad en que les tocó nacer; y por consiguiente, dificultando las condiciones de realización de sus mismas vidas. Y es que existe una gran dificultad en intentar subjetivar una experiencia a nivel del origen histórico de un sujeto, que legal y socialmente se totaliza bajo un carácter de execrable.

36 Lic. César Sotomayor (2006). Los derechos de las niñas y los niños en México. Revista de la Escuela Libre de Puebla, No. 3. Biblioteca Virtual del Instituto de Investigaciones Jurídicas de la UNAM (www.jurídicas.unam.mx).
} 
Infancia y biopolítica en México contemporáneo. Del amparo de la ley al abandono.

niño como un ser minusválido o incapaz, dependiente absoluto de los adultos, que debía permanecer bajo un control autoritario y casi irrestricto de ellos, e incluso a su servicio. Dicho estatus podía cambiar solamente hasta que el menor cumpliera la mayoría de edad.

De acuerdo al citado autor, el avance del conocimiento en general, a través de los aportes teóricos interdisciplinarios ha permitido que, en la actualidad, la mayoría de los países cuenten con una visión más clara sobre la importancia de amparar legalmente a la niñez, en función de su papel en la construcción de la madurez y la responsabilidad de los ciudadanos, clave en el sostenimiento y desarrollo de las naciones.

En el caso de México, las reformas legales formales sobre la cuestión dieron comienzo a inicios del siglo xx, y avanzarán generalmente a la par y en acuerdo con la comunidad internacional, siempre orientadas hacia el reconocimiento, normatización y respeto de los derechos de la infancia. Sotomayor propone que los cinco hitos principales de dichas reformas han sido los siguientes:

1- Gobierno constituyente de 1917.

2- Código civil para el DF en materia común y, para toda la república en materia federal, en octubre de $1932^{37}$.

3- La Declaración de los Derechos del Niño, aprobada por la Asamblea General de las Naciones Unidas, el 20 de noviembre de 1959.

4- La Convención Internacional sobre los Derechos del Niño, adoptada por la Asamblea General de las Naciones Unidas, el 20 de noviembre de 1989. Dicha Convención fue aprobada en nuestro país por la Cámara de Senadores del Honorable Congreso de la Unión, el 19 de junio de 1990, ratificada por el Ejecutivo Federal y dada a conocer el 25 de enero de $1991^{38}$.

5 - Ley para la Protección de los Derechos de Niñas, Niños y Adolescentes, aprobada en 2006.

El autor sostiene que este último hito, en tanto que ley federal que ampara a la infancia en la totalidad de los estados del país, — precisamente a través de la garantía de sus derechos- es el que lograría materializar los lineamientos básicos previamente establecidos por la Constitución General de la República Mexicana. Ésta, en su versión actualizada establece en su artículo cuarto, párrafo séptimo al noveno que:

Los niños y las niñas tienen derecho a la satisfacción de sus necesidades de alimento, salud, educación y sano esparcimiento para su desarrollo integral.

${ }^{37}$ Puede pensarse que Sotomayor se refiere al artículo 17 que, sin referirse directamente a la población infantil, protegía del abuso y la explotación a cualquier mexicano en función de su "suma ignorancia, notoria inexperiencia o extrema miseria". Recuperado el 27 de junio de 2013, desde biblio.jurídicas.unam.mx.

${ }^{38}$ En el apéndice del presente trabajo se especifican los derechos del niño que establecieron estas dos últimas legislaciones internacionales sobre la infancia. 
Los ascendientes, tutores y custodios tienen el deber de preservar estos derechos. El Estado proveerá lo necesario para propiciar el respeto a la dignidad de la niñez y el ejercicio pleno de sus derechos.

El Estado otorgará facilidades a los particulares para que coadyuven al cumplimiento de los derechos de la niñez.

Tras haber considerado, ya sea niña o niño, a los menores que tienen 11 años o menos, y adolescentes a quienes tienen de 12 a 17 años, la ley del 2006 les asegura a todos ellos un desarrollo pleno e integral, la oportunidad de formarse física, mental, emocional, social y moralmente en condiciones de igualdad. Además, — dice el autor - es importante mencionar que, por primera vez se señalan por disposición de la mencionada ley y de manera específica...

...situaciones como las obligaciones de madres, padres y de las personas que tengan a su cuidado niñas, niños y adolescentes (se presuponen maestros), obligaciones que entre otras son: proporcionarles vida digna, recreación, protección contra el maltrato, abuso, agresión, etcétera. Asimismo se establece a favor de la infancia los derechos de prioridad, a la vida, a la no discriminación, a vivir en condiciones de bienestar y a un sano desarrollo psicofísico, a ser protegidos en su integridad, en su libertad y contra el maltrato y el abuso sexual, a vivir en familia, a la identidad, a la salud, a la educación, al descanso y al juego, a la libertad de pensamiento y a una cultura propia.

$[\ldots]$

En cuanto a las sanciones para las infracciones, se establece plena libertad para que la federación, estados y municipios las determinen, en el ámbito de sus competencias, debiendo ser instancias especializadas con funciones de autoridad para la efectiva procuración del respeto de tales derechos.

Es así como el gobierno federal ha quedado obligado, desde entonces, a promover la adopción de un programa nacional para la atención de los derechos de la infancia y la adolescencia, a partir del cual, las diferentes entidades federativas y municipios del país deben impulsar acciones para lograr una cultura de protección de los derechos de la infancia. En ese sentido, la Ley para la Protección de los Derechos de Niñas, Niños y Adolescentes (2006), actualmente ofrece un cimiento y un marco jurídico firmes a la relevante labor que el Sistema Nacional para el Desarrollo Integral de la Familia (DIF) ha venido desempeñando, desde varias décadas atrás, en la línea de la procuración de la defensa de los derechos de los menores de edad.

Por tanto, la opinión concluyente de Sotomayor es que este grado de avance legislativo, del sistema jurídico mexicano, es "ahora lo suficientemente eficaz para proteger sus garantías (de los 
Infancia y biopolítica en México contemporáneo. Del amparo de la ley al abandono.

niños y niñas), sus derechos y atender sus necesidades de desarrollarse y crecer plena, espontánea y libremente". No obstante, acotará lo siguiente:

...los derechos de los niños y las niñas son plenamente reconocidos por el gobierno y los ciudadanos, mas lo que hace falta es una mayor difusión de los mismos, aparejada con una difusión de las obligaciones básicas, comúnmente reconocidas por los padres de familia a sus hijos, en virtud de que los infantes deben conocer sus derechos, pero también deben reconocer sus obligaciones.

Las instituciones públicas y las ONG están haciendo un esfuerzo importante, pero creo firmemente que una gran parte de esta obligación cívica, recae en la sociedad civil, que no sólo debe ser crítica pasiva, sino que debe ser crítica proactiva, propositiva y sobre todo muy participativa, denunciando la violación a los derechos, fomentando su respeto y presionando para la aplicación de las sanciones correspondientes. Porque esto no es obligación sólo del "gobierno", sino que de toda la sociedad; si lo logramos los integraremos a ella y les permitiremos pleno goce de sus derechos como seres humanos.

\section{El decir de la acallada experiencia de Ilse Michel Antecedentes: fragmentos del litigio entre una pareja parental}

A principios de 2009 fue publicada la noticia acerca de una niña, Ilse Michel Curiel Martínez ${ }^{39}$, de entonces diez años de edad" ${ }^{40}$, quien presuntamente había desaparecido del "Albergue Casitas del Sur”, en la Ciudad de México. Su abuela materna, Ardelia Estrada de Martínez, y su madre, Mayra Azucena Martínez Estrada, habían hecho la denuncia a las autoridades del gobierno capitalino, en el intento de que la menor les fuera devuelta.

Un hecho del cual se habló muy poco en las crónicas difundidas es que, años antes, al parecer a inicios de 2005, Mayra había iniciado un juicio legal ante los tribunales, en contra Iván Curiel, su ex-pareja y padre de su hija - ya por entonces involucrado en una nueva relación-, para tratar de retirarle la custodia de esta última, en respuesta a que, en una ocasión en que él se encontraba a cargo, le había negado ver a la niña.

Sin embargo, el acontecimiento más sonado como el que dio inicio a lo que posteriormente sucedió a Ilse Michel, es que en junio de 2005, su padre había recurrido a la Procuraduría General de Justicia del Distrito Federal (PGJDF), para hacer una denuncia en la que acusaba, por una parte, a sus propios padre y hermano, — quienes, por algún tiempo habrían estado al cuidado de Ilse-, de haber abusado sexualmente de la pequeña y, por otra, a la madre de ésta, por presunta violencia y maltratos también contra la niña. Para Iván Curiel, posiblemente se trataba de devolver el "golpe legal" a Mayra Martínez, pero a la vez, él lanzaba otro "golpe" contra miembros de su propia familia. Y sí, los progenitores de Iván se habían separado poco tiempo atrás, y se dice que

\footnotetext{
39 "Michel" no es su apellido, sino su segundo nombre de pila, escrito tal y como se le ha dado a conocer.

${ }^{40}$ Nació el 10 de agosto de 1998. A la fecha tendría 15 años.
} 
su madre le había aconsejado hacer tal acusación contra su propio ex-marido e hijo. Sin duda, soplaban entonces fuertes vientos de desgarramiento de ese entramado familiar, haciendo que lo que pudieran haber sido acciones emprendidas por los padres y la abuela paterna de Ilse, en dirección a defender y proteger a la niña, tanto como a su respectiva relación con ella, a su vez fueran parte de una declarada guerra pasional de despecho y venganza, de mutuos ataques de imputaciones y descalificaciones en los que Ilse Michel, cual si fuera el "botín" en disputa, habría quedado finalmente en la posición más vulnerable de todas, justo entre el fuego cruzado de ese campo de batalla. Todo indica que, bajo esas circunstancias, al interior de ese mundo privado no fue localizable figura de autoridad alguna a cuya experiencia y ayuda apelar, como tampoco otros medios de conciliación y resolución; tuvieron que recurrir al aparato de la justicia gubernamental.

Para el juez en turno, no había hecho falta más que "tomarles la palabra" a esos jóvenes padres, para determinar que era necesario retirarles a ambos la custodia de su hija, mientras se realizaban las averiguaciones legales pertinentes, dada la magnitud de las acusaciones de que se trataba. Como resultado de ello, el 13 de junio de 2005, personal de la PGJDF se llevó por la fuerza a la menor, de casa de uno de sus familiares, y la condujeron a lo que sería en adelante su prolongado internamiento en el Albergue Temporal de la misma institución ${ }^{41}$. Ahí, quedaría privada de su libertad y totalmente aislada de sus lazos familiares, volviéndose objeto de investigación por parte de expertos en varias disciplinas, quienes le practicarían diversos interrogatorios, evaluaciones y peritajes. Era como si fuera una indiciada por la comisión de un grave delito.

\section{La operación discursiva del internamiento de la niña y sus performancias: primera transformación}

Cabe destacar precisamente que, a través de tal medida de internamiento en el Albergue de la Procuraduría, el Estado mexicano ejercía su facultad para, bajo tales circunstancias — en que se determinaba que la menor se encontraba en una situación de riesgo para su integridad-, expropiarla de su familia y tomarla completamente bajo su guarda provisional. Sin embargo, importa localizar cierta operación discursiva que entonces se habría puesto en marcha.

A partir de las declaraciones iniciales de los progenitores de Ilse Michel ante la PGJDF y, años después, ante los medios de comunicación ${ }^{42}$, es posible conjeturar que, en la experiencia de la menor al interior de su complicada vida familiar, ella, su cuerpo, habrían ido cobrando para sus padres más la figura de aquello que motivara y vehiculizara la tensión desbordante de su mutua y fracturada relación, y menos la de la hija niña que, -se supone y pese a todo- seguía estando a cargo de ellos. Todo apunta a que dicha transformación no habría sido impedida por las distintas formas de relevo que, en el cuidado de la pequeña habrían venido efectuando varios de los parientes más cercanos, por ambos costados parentales.

\footnotetext{
${ }^{41}$ Por cierto, actualmente ha modificado su nombre por: "Centro de Estancia Transitoria para Niños y Niñas".

${ }^{42}$ De las cuales se hablará a lo largo de esta sección.
} 
Infancia y biopolítica en México contemporáneo. Del amparo de la ley al abandono.

No obstante, una vez que Ilse había sido llevada a constituirse en "caso" para la institución gubernamental de la justicia, su experiencia cobraría una nueva dimensión, también de doble cara y efectos de largo alcance, pues, en vistas a que "se la quería proteger", se emitía el juicio tajante, totalizador, que oficialmente la definía como "una niña maltratada". Desde ahí, Ilse era "una menor que había qué proteger...", sí, pero ahora del "peligro" que representaba no sólo la relación con su papá y su mamá, con su abuelo y su tío paternos, — todos ellos acusados de ciertas faltas, algunas de ellas penalizables - , sino de toda su familia extensa, dado que la medida jurídica que se había tomado con la menor (el internamiento), en los hechos y de un día a otro, habría puesto a cada uno de sus miembros en entredicho y bajo sospecha, sin establecer salvedad, excepción o matiz algunos.

Los efectos de tal operación a nivel del discurso, de acuerdo a los ulteriores acontecimientos, marcaron determinantemente el devenir de la menor, y harán evidente que aquélla planteó un sesgo que, por lo menos podría calificarse de incauto exceso, en más de un sentido. Efectivamente, la imposición de esta nueva "condición" tanto sobre la niña y su cuerpo, como concomitantemente de su propia y desde entonces cuasi deshabilitada red de parentesco, materialmente la desprotegería y vulneraría, al coartar su soporte y protección en la vida proveniente precisamente de esa relación con los suyos, de las maneras singulares como éstos, - más allá de cualquier ideal de normalización de la familia y de los deberes de la crianza - habían podido ser tales hasta antes de ese momento ${ }^{43}$.

Mientras transcurrió la estancia de Ilse en el Albergue Temporal de la PGJDF, los jueces a cargo evaluaron si existían delitos y culpables que castigar, y presuntamente también, si había condiciones para que, en algún momento se autorizara cierta modalidad de reinserción a la familia de la menor, que pudiera garantizar el bienestar integral de ésta última. Es decir, teóricamente y conforme a la ley y sus procedimientos, en esta primera institución de internamiento infantil, todavía se concedería al tejido de la familia, un resquicio de posibilidad para probar legal y científicamente ${ }^{44}$ que pueden reconformarse y elaborar una especie de nuevo "nudo" o "nido", capaz de sostener su interés por recuperar y acoger "verdaderamente" al menor en cuestión, comprometiéndose en responsabilizarse por él en adelante. Sólo en caso contrario, la custodia familiar se pierde definitivamente, y al niño o niña se le tiene que canalizar a otra instancia institucional que se encargue de ellos en forma más permanente, incluso gestionando y supervisando eventualmente su proceso de adopción por unos padres sustitutos.

En ese sentido, resultó que los estudios y deliberaciones judiciales llevaron a concluir que las denuncias de abuso sexual que señalaban al abuelo y al tío paternos, carecían de fundamento y por ende, quedaban descartadas. En 2006, la madre de la niña también fue absuelta de las acusaciones por maltrato. Mayra Martínez, de hecho refiere que su hija le había confesado ulteriormente

\footnotetext{
${ }^{43}$ Maneras que, por cierto habrá que reconocer, no son poco frecuentes en nuestra sociedad y en otras tantas.

${ }^{44}$ Es decir, ante la observación y evaluación de los especialistas en las disciplinas del "alma", entiéndase: psiquiatras, psicólogos y trabajadores sociales, entre otros.
} 
que Iván, su padre, la había obligado a ratificar tales declaraciones, a pesar de que eran falsas. $A$ posteriori, esto le permitió a la abuela materna decir públicamente: "Ilse entró [al Albergue de la PGJDF] sana, sin huellas de violencia. Ella no tenía nada, y así lo certificaron antes de que entrara ahí, pero se la llevaron acusándonos de que estaba expuesta a un entorno de violencia..." ${ }^{\text {45. Sin }}$ embargo, al respecto habrá que decir que, aún sin esas huellas jurídicamente detectables de heridas y abusos ejercidos en su alma y su cuerpo, a manos de los adultos a su alrededor, dicha confesión de la niña a su madre dejaba entrever esas otras formas hirientes de intercambio con sus padres, ahí donde ambos, mutuamente "amarraron navajas" con ella.

A pesar de las ya referidas absoluciones legales, durante los casi dos años en que inexplicablemente se prolongó el internamiento de la niña en el citado albergue, se han documentado las visitas que, al menos los abuelos maternos y la madre le hicieron quincenalmente, conforme a los lineamientos establecidos por la propia institución ${ }^{46}$. En esas ocasiones, Ilse Michel era llevada a un cubículo especial donde, a manera de cámara de Gesell, sus familiares podían verla detrás de un vidrio que, del lado de ella se hacía un espejo que le impedía mirarlos. Tampoco era posible que hablaran. Sólo una vez, — relató Ardelia Estrada - sabiendo que ellos ya estaban ahí, la niña les mandó besos y les dijo que los quería mucho, pero que no la dejaban verlos ${ }^{47}$. Por cierto que, vale observar - estas palabras, así como la presunta confesión a su mamá de haber sido obligada por su padre a acusarla sin fundamento verídico, son los únicos testimonios más o menos directos y creíbles que se tienen de la voz de la menor en aquel tiempo; ambos coinciden en evidenciar la imposición de la voluntad de otro - el padre, la institución, en este caso - sobre ella. Sin embargo, no deja de resultar paradójico apreciar cómo, en el marco del proceso judicial abierto para proteger a Ilse, en función de sus derechos como niña, los relatos puedan hablar tan poco acerca de lo que ella tenía qué decir al respecto.

Al observar la situación institucional del "encuentro" —o más bien dicho, de no-encuentrode la menor internada, con los familiares que manifestaban su interés por mantener contacto con ella, prescrita, ritualizada, "ascéptica", aparece más severa aún que la impuesta actualmente a la gran mayoría de los adultos que compurgan una condena en prisiones mexicanas y en diversos países, en donde, pese a una más o menos rigurosa vigilancia, dentro del calendario semanal o

\footnotetext{
${ }^{45} \mathrm{Cf}$. Fragmento de su testimonio, transcrito en la nota periodística: “Abandonados y discapacitados. El caso de Ilse Michel Curiel Martínez", a cargo de Fernando Camacho Servín, escrita para La Jornada, sección política, del $1^{\circ}$ de diciembre de 2010 , p. 17. De hecho, resulta interesante cómo el autor de la nota incluye a los adultos, junto con los niños, como parte de aquéllos que son abandonados y considerados discapacitados: uno de los casos emblemáticos del 'limbo'en el que se encuentran los niños y adultos que tienen un padecimiento mental, o que son internados en algún centro de tratamiento como si lo recibieran, es el de la niña Ilse Michel Curiel Martínez (...).

${ }^{46}$ No se conocen datos al respecto de posibles visitas del padre y sus respectivos familiares. ¿Qué había pasado con ellos, una vez desestimadas las denuncias?

${ }^{47}$ De acuerdo a lo referido por Francisco Reséndiz, en su nota titulada: "Se perdió entre disputas familiares", publicada en el diario El Universal (versión digital), del miércoles $1^{\circ}$ de abril de 2009.
} 
Infancia y biopolítica en México contemporáneo. Del amparo de la ley al abandono.

mensual, hay lugar para mirarse los rostros entre ellos y quienes los visitan, a tocarse y estrecharse unos a otros, a conversar e incluso a hacerse algunos regalos.

Tal situación lleva a vislumbrar también algunos de los alcances de la ya mencionada "peligrosidad"48 atribuida a los parientes y allegados de los menores que, como en el caso de Ilse, son tomados bajo la custodia del Albergue de la Procuraduría. Es decir, el peligro supuesto a los miembros de la familia en cuestión, precisamente por el lazo que tienen con el custodiado, cobra además otra dimensión: la del potencial para interferir, — más allá de sus intenciones, y a partir de cualquier gesto o acto en su relación con el niño o la niña - en la función investigadora y correctora que es propia de la autoridad a cargo.

Puede deducirse entonces cómo esto pasará también a formar parte de lo que J. Butter (2002) ha planteado como esa carga de significación e inteligibilidad políticas que, a través de los discursos dominantes en una sociedad, se va depositando en los cuerpos ${ }^{49}$; o sea, la materialidad discursiva con que se inviste y se somete no sólo a los adultos, sino muy precisamente también a esa población infantil que ha sido "confiscada" 50 , mediante las prescripciones y prácticas institucionales especificadas. De hecho, bajo esta misma lógica y en nombre de la protección que se les pretende brindar — por la cual, se les aleja del mundo en que han crecido- paradójicamente los menores mismos se ven seriamente implicados también en tal "peligrosidad". Efectivamente, a pesar de que la condición del niño y la niña es la de aprendices e iniciados en el mundo del lenguaje y de todo cuanto éste organiza de lo humano ${ }^{51}$, bajo tales perspectivas jurídicas pareciera como si su edad se la considerara una cita textual de la raíz etimológica del término "infancia": infans — "el que no habla", y por tanto, "el que no sabe". Se supone entonces que no sabe nada todavía, incluso sobre lo que le concierne a él directamente, careciendo así de una voz autorizada sobre las cosas relativas a lo que significa su propio bien: el cuidado de sí mismo, y lo que conviene a su vida. Tal definición implícita del sujeto de la infancia, a partir de ese nivel de carencia, lo plantearía, cierta y altamente dependiente e influenciable de los adultos - los que han estado a su cuidado o de algún modo cercanos a él—y de "su saber", pero que, en el tipo de situación de que se está tratando ahora, son precisamente aquéllos cuyo proceder frente al menor ha sido puesto en cuestión ante las leyes. Es de esta forma como a los niños y niñas se les atribuye una relación con la verdad particularmente vacilante, por lo que serían muy susceptibles a errar sus juicios y a falsear sus testimonios ${ }^{52}$. Así,

${ }^{48}$ Concepto relacionado con los discursos que, de acuerdo a los planteamientos de Michel Foucault, han venido articulando la economía del poder en los dispositivos judiciales y penitenciarios de la modernidad, que opera como índice del "peligro virtual" que ciertos individuos pueden representar para la sociedad y el orden en que se funda, en función de su llamado "perfil criminológico". Cf. Foucault, M. Vigilar y castigar. Nacimiento de la prisión. Op. cit.

${ }^{49}$ Cf. Butler, J. Cuerpos que importan... Op. cit.

${ }^{50}$ Valga la utilización del término, dado que estrictamente se aplica sólo a los bienes.

${ }^{51}$ Cf. Agamben, G. Infancia e historia. Op. cit.

${ }^{52}$ Este planteamiento encuentra parte de su fundamento en lo que se desprende de la propuesta de J. Butler, en: Cuerpos que importan, Op. cit., en cuanto a la suposición e imposición de una especie de abstrusa materialidad -significación, inteligibilidad e 
dentro de su estancia en el Albergue de la Procuraduría no puede admitírseles poseer una voluntad propia y un nivel de responsabilidad sobre sus actos, así como de participación en las decisiones que les afectan. En síntesis, bajo tal óptica, la comúnmente idealizada figura de inocencia propia de la edad infantil, vulnerable e indefensa, e incluso victimada, amenaza permanentemente con mutar hacia su opuesto: un pequeño infractor en potencia, que habrá que vigilar, corregir y educar en lo adelante ${ }^{53}$.

\section{La abuela materna frente al poder gubernamental: ella se propone tejer el nuevo} "nudo y nido" para recuperar a llse Michel

Ardelia Estrada, la abuela por el costado materno declaró a los medios que la última vez que vio a su nieta en el Albergue de la Procuraduría fue el 15 de abril de 2007. A pesar de que ella había manifestado reiteradamente su deseo de que se le concediera a ella la custodia de su nieta, la entonces directora de la institución de internamiento, Lorena González, se había rehusado a ello bajo el argumento de que Ilse "no se encontraba bien y todavía no había terminado su 'tratamiento"s4 en la institución, por lo que no quería arriesgarse a que, en caso de entregársela en ese momento, la pequeña tomara el camino de las drogas, el suicidio, o bien huir del hogar". Unas cuantas semanas después, le fue informado a la señora Estrada que, por orden de la fiscal del caso en ese momento, Alicia Azzolini, —y evidentemente, sin haber dado aviso a ninguno de sus parientes-, la menor había sido enviada a un albergue privado ${ }^{55}$. Se trataba del llamado "Albergue Casitas del Sur" que estaba situado en la delegación Tlalpan, y operaba bajo responsabilidad de miembros de la llamada Iglesia Cristiana Restaurada (ICR), aunque, al parecer, con subvención gubernamental ${ }^{56}$. Las políticas marcaban que la estancia de los niños y niñas que eran ahí canalizados, no tenía ya un carácter temporal, pues se trataba de quienes definitivamente habían sido abandonados por sus familias, o se había probado "suficientemente" que no contaban con nadie que tuviera condiciones de asumir la responsabilidad de cuidar adecuadamente de ellos.

Pero, entonces, ¿cómo es que se había tomado tal determinación de enviar a Ilse a ese lugar si, - de acuerdo a lo que ya fue mencionado antes - estaba prescrito que una vez que un menor ha llegado al Albergue Temporal de la Procuraduría, solamente un juez de lo familiar, ya concluido el proceso legal correspondiente, podía autorizar su salida para ser devuelta a su familia o bien, su canalización a otra institución? De acuerdo a lo que ha venido siendo expuesto, era claro que esta última no era la situación de Ilse Michel, puesto que no se contaba todavía con la resolución final

importancia en el campo político- sobre aquellos cuerpos humanos que no corresponden al modelo dominante de conocimiento en Occidente "falogocéntrico", característicamente masculino y adulto.

${ }^{53}$ Es perceptible el carácter mixto: jurídico, médico y moral, en el origen probable de toda esta construcción ideológica acerca del niño. Cf. Foucault, M. Los anormales (2002). México: Fondo de Cultura Económica.

54 Término textual recabado del testimonio de la señora Estrada.

55 Paradójicamente, ese traslado -funesto, de acuerdo a lo que sucederá a partir del mismo- había ocurrido el 30 de abril, fecha que en el calendario de celebraciones en nuestra cultura señala como "Día del niño". 
Infancia y biopolítica en México contemporáneo. Del amparo de la ley al abandono.

del juez en turno, y el rumbo tomado por su respectivo proceso judicial tampoco apuntaba a que quedara descartada la posibilidad de que la custodia fuera devuelta, esta vez a otro miembro de su propia familia. Lo que el análisis de la información dada a conocer en torno a la investigación oficial sobre "el caso" de Ilse Michel Curiel Martínez lleva a pensar, es que en realidad no había habido argumentos técnico-legales fundados, sostenibles y explícitos que hubieran podido ser esgrimidos en su defensa por parte de los funcionarios y personajes implicados en tal decisión. Sólo se cuenta con la versión de lo que a Ardelia Estrada le habían dado como respuesta a su petición de recuperar a su nieta: primero la directora del Albergue Temporal de la Procuraduría, — quien opinaba como docta especialista en materia de esos asuntos - y posteriormente, la directora del Albergue Casitas del Sur. Sin embargo, todo parece indicar que tales argumentaciones no eran legalmente válidas ni suficientes para haber hecho lo que se hizo, y que en cambio, más bien serían pantalla de otra clase de razón inconfesable.

\section{Irrumpe la operación del Albergue Casitas del Sur Segunda transformación del cuerpo de llse}

Hoy sabemos que el Albergue Casitas del Sur podría considerarse una especie de trágica realización de esos lugares misteriosos y siniestros de los que, bajo diferentes formas hablan algunas narraciones y mitos a lo largo de la historia de la humanidad. Se trata de oscuros y truculentos espacios en los que caen y quedan atrapados niños que por diferentes caminos se han extraviado, y que a partir de entonces, el mundo pierde - a veces para siempre - , una vez alejados del cuidado de incautos padres, y que el vigilante ojo divino o de la autoridad de la ciudad, inexplicablemente se ha cerrado.

En efecto, desde ese momento, Ilse Michel no había pasado a quedar a cargo de miembros de la Iglesia Católica Restaurada, sino a ser parte de una población cautiva de niños de su propiedad y dominio, al parecer, esta vez en nombre de Dios. Ya no hubo oportunidad para la familia Martínez Estrada de visitar y mirar a Ilse ni siquiera a través de un vidrio-espejo. Para tener alguna noticia de ella, la madre y la abuela materna telefonearían repetidamente a la directora del Albergue en esa época, Elvira Casco Majalca, quien les reportaría que: "la niña se encontraba bien, pero que no deseaba regresar con su familia"; por tal motivo se negaba rotundamente a permitirles verla, menos aún a entregárselas, pretextando la supuesta necesidad de prevenir nuevos maltratos y abusos sexuales por parte de sus propios familiares ${ }^{57}$. Cuando Ardelia, preocupada e inconforme, intentó forzar un tanto las cosas y acudió directamente a "Casitas del Sur" para exigir ver a su nieta, nunca

${ }^{56}$ ¿Formaría parte de esos incomprensibles acuerdos de dudosas motivaciones, promovidos y efectuados "en lo oscurito” por un Estado presuntamente laico, en relación con organizaciones a toda luz confesionales? La expresión coloquial entrecomillada alude precisamente al compromiso manifestado públicamente por parte del expresidente de la república mexicana, Vicente Fox, en el sexenio 2000-2006, relativo a que en su gobierno no se harían negociaciones "en lo oscurito".

${ }^{57}$ Atendiendo únicamente a lo que para entonces ya había dictaminado el proceso judicial en torno a Ilse Michel, ¿en base a qué es que la señora Casco recurría todavía a esas desestimadas acusaciones hacia la familia de la niña? 
se le abrió la puerta. Entonces, apelando de nuevo a la responsabilidad gubernamental, la señora Estrada recurrió a denunciar repetidamente ante la Procuraduría y el DIF, la irregular posición de los dirigentes del albergue. Sin embargo, hubo de pasar más de un año para que la insistencia de la abuela obtuviera una respuesta oficial a su favor. Efectivamente, en agosto del 2008, la juez 16 de lo familiar, Gloria Rosa Santos, dio el fallo en el que finalmente se le otorgaba la custodia de Ilse Michel a su abuela materna, emitiendo a la vez la orden judicial para que la niña le fuera entregada. No obstante este logro significativo por el cual, el Estado mexicano finalmente reconocía y simbólicamente restituía la autoridad legítima de esta mujer sobre su nieta, (una vez que a los padres de ésta se les había retirado la custodia), tal reconocimiento no tuvo efectos ni oportunidad de realizarse. Durante los meses siguientes, la posición de los directivos del Albergue Casitas del Sur se mantuvo silenciosa e inalterable. Apenas a principios de 2009, y en atención a la nueva personalidad legal de la señora Ardelia Estrada, aceptaron hablar con ella, pero sólo para comunicarle que Ilse Michel había desaparecido desde septiembre del año anterior. Además de dar a conocer la gravedad misma de este hecho, dicha versión dejaba entrever también graves ocultamientos e irregularidades, pues entonces habrían tardado alrededor de cuatro meses para enterar a la abuela materna de la niña acerca de tal hecho trascendental y desafortunado que, según, pues, los tiempos y procedimientos institucionales, había "vuelto a ser" de su completa incumbencia. (Se entrecomilla esta expresión, dado que en realidad, Ardelia Martínez no había requerido de un veredicto oficial para ocuparse de su nieta). Además, partiendo de que efectivamente, la "desaparición" de la niña había ocurrido en la fecha señalada, era inevitable aventurar que, si los miembros de la ICR "a cargo" - ya se advierte en qué forma - le hubieran regresado a Ilse oportunamente, en agosto, tal y como correspondía por derecho, entonces se habría podido ganar la carrera a los acontecimientos. No obstante, la cuestión evidenciada era aún más compleja y delicada, puesto que, tras haber adquirido el ya mencionado estatus jurídico de "menor rescatada de su propia familia", de "niña interdicta y amparada por el Estado garante de sus derechos constitucionales", repentina, inexplicable y paradójicamente, en el Albergue confesional autorizado, a ella se le había cambiado al estatus extremo, radical de "niña desaparecida oficialmente". De habérsele incautado para salvarla de la ignominia, luego se la había perdido, invisibilizado y silenciado completamente para ella misma y para los suyos, para la sociedad en general. ¿Qué consecuencias habría tenido para la vida de Ilse Michel ese segundo cambio de "estatus”? ¿Dónde localizar ahora su voz, hablándonos de lo que vivió a lo largo de todo este complicado proceso para "protegerla"?

Pero, detengámonos asimismo a preguntar, en el contexto mismo de los hechos, qué significaba la declaración de los dirigentes del Albergue Casitas del Sur, acerca de la "desaparición" de Ilse. "Desaparecer" es una acción plenamente referencial, sobre todo en función de sus agentes pasivos, de quienes lo viven y sufren directa e indirectamente; es decir, jurídicamente hablando, quien fue el agente activo de una "desaparición" — como puede suponerse existió en este caso, bajo la forma de una cadena de irresponsabilidad, corrupción y delito, probablemente perpetrados éstos por fun- 
Infancia y biopolítica en México contemporáneo. Del amparo de la ley al abandono.

cionarios y operadores a niveles e instancias diversos - , tiene una idea, o bien, sabe perfectamente dónde fue a parar el llamado "desaparecido", conoce al menos el umbral de lo que fuera su destino. Pero, entonces, el hacer de ese agente activo tiene otros nombres específicos, que generalmente estarán asociados a lo prohibido. Entonces, ¿qué papel tenía en esa agencia el sujeto que admitía públicamente que la niña se había esfumado de la institución bajo su responsabilidad, donde se la había "albergado"? De esa manera, la declaración de la "desaparición de Ilse Michel" implica para aquéllos de su familia que la quisieron de alguna manera, solamente un descarado eufemismo de lo que en realidad sucedió, un fracasado intento de nombrar acaso y "explicar" la pérdida por ellos sufrida que, ya fuera ésta temporal o para siempre, ciertamente no es una mera cuestión retórica. Hasta ahora, frente a Ilse misma, tal declaración instaura una enorme deuda de cuestionamientos sin respuesta a su altura.

Entonces, tratando de avanzar un poco más y siguiendo paso a paso la secuencia de esta experiencia de Ilse Michel que hasta aquí ha sido planteada, ¿cómo dar cuenta del hecho por el cual, a final de cuentas, dentro de esa marcha de la maquinaria interinstitucional mexicana de protección a la infancia, a Ilse se le transformó de facto de niña protegida en base a sus derechos constitucionales, a un cuerpo expuesto, una vida desnuda de la cual dispuso el capricho de un poder sin ley? ¿En qué medida habría que pensar que la captura absoluta de la niña al interior de una cierta figura jurídica y la concomitante inhabilitación y exclusión de los lazos familiares, operadas por la primera "metamorfosis", había sido paradójica y precisamente premisa y condición de la segunda?

\section{Y entonces Ilse Michel se volvió noticia y motivo de escándalo para los mass media... "La maquinaria" legal busca solucionar los "des-Perfectos" para seguir funcionando}

La situación sería entonces multicitada por los medios de comunicación en nuestro país, debido a lo cual, el 29 de enero de 2009, el procurador de Justicia capitalino daría la orden de llevar a cabo un cateo del "Casitas del Sur", con el fin de "rescatar" a los 116 (en otras notas periodísticas se habla de 126 o 128) menores que ahí se encontraban, incluidos 16 pequeños entre 1 y 3 años de edad. Los niños y niñas fueron encontrados deshidratados y en deplorables condiciones de todo tipo; algunos de ellos gritaban llenos de pánico: “¡Esto es pecado! ¡Esto es el fin del mundo!”, mientras eran trasladados al albergue del DIF nacional, de donde posteriormente serían canalizados a diversas instituciones donde - se dijo- "se iba a tratar el daño psíquico de haber estado en el citado albergue"s8. Al respecto, ¿cómo no pensar que tal refugio operaba en realidad, a la manera de un campo de concentración en miniatura y para niños? 59

${ }^{58}$ Quepa mencionar, por cierto que, aún en esta circunstancia, los padres que reclamaron a algunos de estos niños trasladados, no podrían recuperarlos inmediatamente, debido a lo que ya se ha dicho que la ley marca; es decir, de cualquier forma, se requería la orden de autorización del juez de lo familiar a cargo de sus casos.

${ }^{59}$ La implicación de esta comparación del albergue infantil en cuestión, con los campos de concentración nazis, se esclarecerá mejor en la última parte de este trabajo. 
Dicha incursión de las autoridades permitió efectuar la localización de una niña con cierto parecido a la menor en cuestión, a quien los agentes judiciales preguntaron si ella era "Ilse Michel", a lo que inicialmente ella respondió que sí, pero más tarde corrigió que se llamaba "Josseline"60. En el ínter de ese interrogatorio, otros niños del albergue le sugerían pícaramente: "Ya di que eres Ilse..." ${ }^{61} \mathrm{Al}$ principio, la madre y la abuela creen reconocer en ella a la niña, mas no se sienten del todo seguras; había pasado ya tanto tiempo sin verla de cerca... Sin embargo, las pruebas periciales de ADN, finalmente indicarán que no era a quien ellas buscaban.

Desde entonces: nada, ningún rastro fidedigno para lograr encontrarla. Ilse Michel Curiel Martínez continuaba "desaparecida". La "constatación" de este hecho a partir del cateo de enero de 2009, hizo que las autoridades gubernamentales se dieran cuenta que un total de catorce menores que habían sido ingresados en albergues de la ICR, ubicados en diversos estados de la República, estaban en una situación semejante; tan sólo en el "Casitas del Sur" en el DF, sumaban siete.

Interrogados en torno al caso de Ilse, los directivos de este albergue dieron distintas y contradictorias versiones: que la niña podía haberse escapado, — a pesar de que, por parte de ellos no hay antecedente alguno de haber reportado ese hecho supuesto-; o bien, que quizás había sido dada en adopción, argumentando presuntamente que "ella había pedido ser adoptada por otra familia". Una última explicación que dieron, es que había sido canalizada a otra institución.

Todas estas posibilidades esgrimidas en su propia defensa por los encargados y miembros de ICR, hacían surgir algunas dudas; por ejemplo en torno a que, teniendo a Ilse Michel bajo su responsabilidad, "no sabían" dar cuenta cierta sobre qué había ocurrido con ella. Era claro que tal "ignorancia" dejaba en la superficie la forma en que ellos "albergaban y protegían" las vidas y el destino de los infantes recluidos en su institución. Pero, por otra parte, ¿cómo es que el gobierno mexicano le habría delegado, regalado la tutela de ciertos menores provenientes del Albergue de la Procuraduría, a los mencionados "refugios" infantiles privados, sin dar seguimiento serio de la situación de cada uno de esos niños y niñas, sin mantener cierta supervisión y los necesarios controles acerca de lo que en tales instituciones de refugio infantil sucede? ¿Qué alcance tenía, pues, la causa de la defensa de los derechos infantiles?, o bien, ¿qué interpretación darle a la magnitud de dicha omisión de la institución judicial?

Al paso de ya más de cuatro años, las crónicas informativas se han ido olvidando paulatinamente de Ilse Michel Curiel Martínez. Sólo el buscador predeterminado de Google, muy raramente

${ }^{60}$ Las resonancias de esta situación, en la que a un niño que ha sido alejado o privado de los lazos de protección parental y familiar, se le plantea la cuestión de su identidad como un elemento de sí, eventualmente maleable o mimetizable -de acuerdo a las circunstancias que se encuentre viviendo, y en función de su propia supervivencia-, y que incluso le llega a ser arrebatado por la arbitrariedad y el abuso del poder de otro (la autoridad oficial misma que toma al menor a su cargo, por ejemplo), evocan un caso real ocurrido en los Estados Unidos, llevado a la cinematografía por el director Clint Eastwood: El sustituto (2008).

${ }^{61}$ Asociado a lo planteado en la nota al pie inmediata anterior, ¿estos niños le sugerían a Josseline jugar el juego de esos adultos, apostando a que quizás mintiendo acerca de su nombre, "siendo" quien aquéllos esperaban que fuera, llegara a encontrar, por ejemplo, unos "padres" que finalmente la acogieran? 
Infancia y biopolítica en México contemporáneo. Del amparo de la ley al abandono.

vuelve a dar aviso de la aparición de una nota marginal que dice que la niña continúa desaparecida, y que su abuela materna sigue perseverante en su búsqueda. Entretanto, en el país, miles de menores como ella, de azarosos modos han seguido su ominosa trayectoria, y las fotografías de los rostros de algunos de ellos se siguen acumulando en los registros de las instituciones oficiales responsables de impartir justicia, y de la protección a la familia y a la infancia, tanto como de organismos no gubernamentales, sin que la gran mayoría vuelva a aparecer. No obstante, retomando, en lo que toca a la propia Ilse, lo que se sabe hasta ahora de lo que se obtuvo de las averiguaciones efectuadas en dirección al presunto intento de encontrarla, así como de descubrir la verdad de los hechos, fue otra batalla ${ }^{62}$, esta vez de deslinde de responsabilidades y recíprocas acusaciones entre los diversos personajes e instituciones involucradas, particularmente aquéllas de carácter oficial y un número importante de miembros de la ICR. Pero, en este caso, siendo la PFJDF juez y parte, tras haber sido responsable de la derivación de la niña a un albergue de muy dudosa forma de operación, emprendió varias líneas de investigación que principalmente apuntaron hacia los dirigentes del mismo. A finales de septiembre de 2009, la PGJDF requirió a Reintegración Social A. C., nombre con el que se da a conocer el grupo de "trabajadores voluntarios" del Albergue Casitas del Sur, adscrito a la ICR - , las pruebas de que Ilse fue dada en adopción. Hasta donde se sabe, dichas pruebas no pudieron ser entregadas.

Por su parte, seguidores de la ICR, vinculados al Albergue Casitas, regresaron "la papa caliente" sobre todo a Marcelo Ebrard, entonces jefe de Gobierno del DF y a Miguel Mancera, exprocurador de Justicia del DF, acusando directamente a la propia Procuraduría de otorgar adopciones ilegales a cambio de dinero. Sus consignas han sido: “Ellos son los que venden niños a violadores!”, "Ebrard protege pedófilos", etcétera ${ }^{63}$.

Sin embargo, a la fecha, se encuentra en prisión Antonio Domingo Paniagua Escandón, uno de los líderes fundadores de la ICR, junto con 7 personas más que están en proceso penal. Por otra parte, existen órdenes de aprehensión contra el prófugo Jorge Erdely, — también líder fundador de la también llamada secta de "Los Perfectos"_-64, así como contra otro grupo de personas ligadas a la misma corporación religiosa, por sus vínculos con la desaparición de varios niños ${ }^{65}$ que habrían sido internados en los albergues que ellos mantenían en diversos estados de la República. Por desgracia, dichas desapariciones han sido ligadas al caso penal del empresario Succar Kuri-Kamel

\footnotetext{
${ }^{62}$ Se hace alusión al inicio de esta historia, en el que habría sido también la batalla entre los padres de la niña, por causa de la defensa de ella, lo que los había llevado a apelar a la mutua denuncia ante la Procuraduría.

${ }^{63}$ Declaraciones y afirmaciones de miembros de Reintegración Social A. C., dadas a conocer a través de los medios electrónicos.

${ }^{64}$ Quien, de acuerdo a la reportera Carmen Aristegui, ha venido haciendo amenazas contra los periodistas que lo investigan a él y a su iglesia. Este grupo evangélico fue fundado por Jorge Erdely Graham, especialista en teología y afincado en Canadá, desde donde controla la red de congregaciones religiosas y casas hogar distribuidas en México y con nexos en Centroamérica, Estados Unidos, Europa, Asia y algunos países sudamericanos. Cf. Martínez, S. (2009). Se venden niños. México: Temas de hoy.

${ }^{65}$ Cuyo número oscila entre 14 y 22 infantes, aproximadamente.
} 
Nacif y del exgobernador de Puebla, Mario Marín, quienes presumiblemente están involucrados con una red criminal organizada precisamente alrededor de la comisión de los delitos de pederastia y abuso infantili6.

Los padres y los abuelos de Ilse Michel, apoyados por distintas organizaciones de derechos humanos y de protección a la infancia, también hicieron declaraciones y acusaciones contra diversos funcionarios del gobierno capitalino y de la ICR, sobre todo a lo largo de 2009. En ese entonces, desorientados y desconcertados entre las diversas y contradictorias pistas e informaciones que han recibido, reconocieron ante los medios de comunicación los horizontes de posibilidad de lo que pensaban que pudo haber sido el destino de la niña. Por cierto que todos esos horizontes eran terribles y abrigaban muy poca o ninguna esperanza: podría ser que hubiera sido dada en adopción, habiéndosele practicado una cirugía plástica que la hiciera irreconocible; o quizás fuera robada del Albergue Casitas del Sur y vendida a través de una red de trata de personas o de tráfico de órganos; incluso, tal vez ella ya no viviera. No obstante, lo que las noticias han reportado es que Ardelia Estrada continúa trabajando por encontrar a su nieta, apelando y exigiendo a distintas instancias oficiales nacionales e internacionales que les sea finalmente devuelta, y que se finquen responsabilidades sobre quienes corresponda.

\section{A manera de cierre provisional...}

La concepción y puesta en marcha del derecho a favor de la protección y el bienestar de la niñez, desde la ventana abierta por los llamados "casos" concretos, plantean un sesgo paradójico importante a considerar y seguir estudiando, a partir del cual, sin que se advierta, en primer lugar podrían estar replicando la violencia y las marcas que las propias prácticas proscritas jurídicamente y perpetradas por parte de su entorno familiar, le habrían impuesto al menor ${ }^{67}$. En efecto, una vez declarado "niño maltratado, y/o abusado, y/o abandonado", los jueces y procedimientos subsecuentes, generalmente "en automático" lo separan de los que serían los suyos, y lo transforman, estigmatizándolo, en "cuerpo del delito": todo en él cuenta y habla en cuanto que signo viviente o eventual prueba incriminatoria (en algunos casos en descargo) de eso que, - se ha dicho ya $-\mathrm{a}$

${ }^{66}$ Ref. El Universal.com.mx, El Kiosko, 31 de marzo de 2009.

${ }^{67}$ A este respecto, resulta interesante recordar y citar a Piera Aulagnier, a partir de su estudio sobre la constitución subjetiva, desde el marco del psicoanálisis, donde distingue dos formas de violencia: primaria y secundaria. La primera, tendría que ver con el hecho mismo de la introducción del infante en el mundo simbólico y del lenguaje que lo antecede, a través de la relación con los adultos que toman a su cargo el cuidado de su vida. Se trata del efecto irremediablemente violento que ejerce el enfrentamiento sin elección del cuerpo del niño, a un orden del significante que le es heterónomo, pero que será clave constituyente de su subjetivación, en el sentido de que le dará la posibilidad de significar e historizar su experiencia, como miembro del mundo humano. La segunda forma de violencia remite a aquellos actos de imposición sobre el menor que, no obstante algunos de ellos sean ejercidos declaratoriamente en nombre de "su bien", resultan ser innecesarios, avasalladores y de-subjetivantes, en cuanto que le arrebatan al niño sus posibilidades de significarse y construirse a sí mismo de un modo honroso y viable en su sociedad; por ello es que tales acciones representan un abuso del poder por parte de los adultos. Cf. Aulagnier, P. (1977). La violencia de la interpretación. Del pictograma al enunciado. Buenos Aires: Amorrortu. 
Infancia y biopolítica en México contemporáneo. Del amparo de la ley al abandono.

la ley sólo le importa; desdibujándose así la línea que distinguiría al menor mismo, de la figura del (o los) presunto(s) culpable(s). Indudablemente, dicha transformación está jugando un papel muy importante en la manera en que, - de un modo que nos parece más que inquietante, y que precisamente, se hace necesario tratar de explicar y tomar nota-, el destino de estos niños, no logra despegarse del que Foucault desplegó que se le imponía al llamado "criminal" o "delincuente"68, e inclusive y por desgracia, es a veces peor aún. Es de esa manera como los niños cuyas derivas en sus vidas particulares los llevan a ser parte de un proceso judicial en su defensa, y a "tener que ser protegidos en exclusiva" por la ley, estarían pasando, pues, de ser "usados", "usufructuados" por la familia, a seguirlo siendo, pero ahora bajo la modalidad que produce el aparato burocrático jurídico. Por desgracia, este modus operandi legal, en cierto modo abandona al menor y lo deja en el desamparo, al abrirle paso a otras modalidades criminales de utilización de los menores, a manos de extraños que llegan a introducirlos como mercancía en el circuito del mercado, y los condena finalmente a la condición de desechos.

La experiencia de Ilse Michel Curiel Martínez agudamente hace virar esta reflexión rumbo a una tesis de Giorgio Agamben (2004) ${ }^{69}$, por cierto, muy cercana a lo propuesto por Butler ${ }^{70}$, en torno a que, en los Estados nacionales de Occidente contemporáneo se está generalizando paulatinamente sobre cada ciudadano, la estructura biopolítica fundamental de la modernidad que, en ese entonces se aplicó sobre ciertos grupos delimitados y, que dio su fundamento a los campos de concentración nazi durante la Segunda Guerra Mundial. Dicha estructura estaba asociada al "dar forma a la vida del pueblo", a través de establecer los límites de "la vida que no merece ser vivida y la que sí lo merece"; o sea, de la determinación jurídica de si quitarle la vida a algunos era o no un crimen, de si esas vidas tenían o no un valor legalmente hablando. De esa manera, actuales apuestas de los gobiernos que se plantean "proteger, mejorar y elevar las condiciones de vida de la población, especialmente la de 'los más vulnerables", en nombre de las prerrogativas que les otorga la ley -y, por supuesto, en base al saber y los avances de la ciencia y la tecnología - y como una preconización de la figura del sujeto de derecho, insospechadamente parecen estar produciendo masas de vidas desnudas, reducidas y sin significación, expuestas a que casi cualquiera pueda disponer de ellas a su antojo e impunemente, precisamente en el mismo lugar donde se decía estarlas "dignificando y cualificando".

No obstante, este trabajo está muy lejos de pretender proponer lo que sería imposible: una detención o retroceso de los avances legislativos en materia de amparo a la niñez. Más bien, busca hacer visible y legible no sólo la interpelación efectuada por la — muchas veces - desafortunada y trágica trayectoria de estos niños, a nivel de la flagrante insuficiencia ${ }^{71}$ de tales modelos jurídicos y cien-

\footnotetext{
${ }^{68}$ Cf. Foucault, M. Vigilar y Castigar. Nacimiento de la prisión (2002). Buenos Aires: Siglo XxI.

${ }^{69}$ Agamben, G. Estado de excepción: Homo sacer II (2004). Valencia: Pre-textos.

${ }^{70} \mathrm{Cf}$. Primera parte de este artículo.

${ }^{71} \mathrm{Si}$ no es que habría que hablar de cuestiones aún peores, tales como el problema de la corrupción generalizada, el crimen organizado, etcétera.
} 
tíficos para encarar las vicisitudes y dificultades que plantea ese continuamente fallido (y pleno de malestar) cuidado de la infancia, por parte de las familias y de las sociedades. Sino, sobre todo se trataría de sostener dicha interpelación a nivel de la tensión irreductible e irresoluble entre cuerpo y política, entre vida humana y ley, convocando, por tanto, a que la voz de los excluidos —excluidos en base al modo como ellos viven, trátese de niños o adultos-, sea también lenguaje y palabra ${ }^{72}$ en los asuntos que les conciernen en cuanto al hacer de sus propios destinos. (Por cierto, le comparto al lector una suposición: quizás de ese modo, felizmente, Ilse Michel no habría llegado a ser materia de este artículo).

Guadalajara, Jal., febrero de 2014.

\section{Adenda: "Ilse Michel Curiel Martínez ha reaparecido". Se abren nuevas interrogantes 73}

El día 6 de marzo de este año, Ilse Michel Curiel Martínez llegó sola, en taxi a las instalaciones de un DIF, en el Estado de México. Las notas periodísticas refieren que, tras algunas averiguaciones, las autoridades a cargo la entregaron a su abuela dos días después. Ella tiene ahora 15 años y se dice que "libremente" ha elegido estar con su madre. Sin embargo, llama la atención cómo, en contraste con la notoriedad que tuvo el escándalo de la desaparición de la menor a nivel de los medios de comunicación, esta vez los noticiarios han hablado bastante poco en torno al asunto, inclusive, no se han difundido imágenes actualizadas de Ilse, como tampoco del imaginado reencuentro con su madre y su abuela. Sólo Mayra Martínez ha hablado en entrevistas telefónicas públicas, relatando someramente que su "gorda no quiere más interrogatorios", pues "se pone muy alterada".

Aparentemente, habiéndosele dicho que su familia la había abandonado, fue adoptada con su mismo nombre por una pareja de la ICR que "la trató bien", pero que la mantuvo aislada completamente del mundo exterior, sin contacto siquiera por vía de la radio o la televisión. Sin embargo, ellos la dejaron irse cuando Ilse dijo: "extraño a mi abuela". Al llegar al DIF el 6 de marzo, quienes la atendieron, le dijeron que no podían ayudarla. Poco después ella insistió, refiriendo que había una recompensa por ella. (¿Cómo es que Ilse sabía esto, de acuerdo a lo que recién se había descrito? Mayra responde que su hija casualmente lo supo por una noticia en la radio... ¿?). Fue entonces que funcionarios tomaron cartas en el asunto y la conducen finalmente a su familia. La madre de la menor dice finalmente que la autoridad judicial "aguarda" al momento en que la menor esté en condiciones de colaborar con las investigaciones ${ }^{74}$.

\footnotetext{
${ }^{72}$ Se alude a esta diferencia aristotélica, — citada por Agamben — entre la "voz" propia de la vida no cualificada, y el "lenguaje" de la vida en la polis. Cf. AGAMBEN, G. Homo sacer: El poder soberano y la vida nuda (2010). Valencia: Pre-textos.

${ }^{73}$ Agradezco a Mercedes Palencia haberme compartido en primera instancia la noticia que da lugar a esta nota de actualización de la experiencia de Ilse Michel.

${ }^{74}$ Se ha hecho referencia hasta aquí a la entrevista con Mayra Martínez, llevada a cabo por Denise Maerker, el 11 de marzo del año en curso.
} 
Infancia y biopolítica en México contemporáneo. Del amparo de la ley al abandono.

Algunas notas periodísticas comienzan a mencionar que Ilse Michel es ahora "víctima del síndrome de Estocolmo"... Tal vez se trate de un esbozo de una nueva figura a imponerle, otro tecnicismo para nombrar la dificultad de ella para reaparecer, o quizás habría que decir que para aparecer por vez primera y tomar una voz propia que, no se sabe si alguno de los actores de este drama esté dispuesto a escuchar. 


\section{Apéndice}

\section{Artículo $1^{\circ}$}

El niño disfrutará de todos los derechos enunciados en esta declaración. Estos derechos serán reconocidos a todos los niños sin excepción alguna ni distinción o discriminación por motivos de raza, color, sexo, idioma, religión, opiniones políticas o de otra índole, origen nacional o social, posición económica, nacimiento u otra condición, ya sea del propio niño o de su familia.

\section{Artículo $2^{\circ}$}

El niño gozará de una protección especial y dispondrá de oportunidades y servicios, dispensado todo ello por la ley y por otros medios, para que pueda desarrollarse física, mental, moral, espiritual y socialmente en forma saludable y normal, así como en condiciones de libertad y dignidad. Al promulgar leyes con este fin, la consideración fundamental a que se atenderá será el interés superior del niño.

\section{Artículo $3^{\circ}$}

El niño tiene derecho desde su nacimiento a un nombre y a una nacionalidad.

\section{Artículo $4^{\circ}$}

El niño debe gozar de los beneficios de la seguridad social. Tendrá derecho a crecer y desarrollarse en buena salud; con este fin deberán proporcionarse, tanto a él como a su madre, cuidados especiales, incluso atención prenatal y postnatal. El niño tendrá derecho a disfrutar de alimentación, vivienda, recreo y servicios médicos adecuados.

\section{Artículo $5^{\circ}$}

El niño física o mentalmente impedido o que sufra algún impedimento social debe recibir el tratamiento, la educación y el cuidado especiales que requiere su caso particular.

\section{Artículo $6^{\circ}$}

El niño, para el pleno desarrollo de su personalidad, necesita amor y comprensión. Siempre que sea posible, deberá crecer al amparo y bajo la responsabilidad de sus padres y, en todo caso, en un ambiente de afecto y de seguridad moral y material; salvo circunstancias excepcionales, no deberá separarse al niño de corta edad de su madre. La sociedad y las autoridades públicas tendrán la obligación de cuidar especialmente a los niños sin familia o que carezcan de medios adecuados de subsistencia. Para el mantenimiento de los hijos de familias numerosas conviene conceder subsidios estatales o de otra índole. 


\section{Artículo $7^{\circ}$}

El niño tiene derecho a recibir educación que será gratuita y obligatoria por lo menos en las etapas elementales. Se le dará una educación que favorezca su cultura general y le permita, en condiciones de igualdad de oportunidades, desarrollar sus aptitudes y su juicio individual, su sentido de responsabilidad moral y social y llegar a ser un miembro útil de la sociedad. El interés superior del niño debe ser el principio rector de quienes tienen la responsabilidad de su educación y orientación; dicha responsabilidad incumbe, en primer término, a sus padres. El niño debe disfrutar plenamente de juegos y recreaciones, los cuales deben estar orientados hacia los fines perseguidos por la educación; la sociedad y las autoridades públicas se esforzarán por promover el goce de este derecho. 


\section{Artículo $8^{\circ}$}

El niño debe, en todas las circunstancias, figurar entre los primeros que reciban protección y socorro.

\section{Artículo $9^{\circ}$}

El niño debe ser protegido contra toda forma de abandono, crueldad y explotación. No será objeto de ningún tipo de trata. No deberá permitirse al niño trabajar antes de una edad mínima adecuada; en ningún caso se le dedicará ni se le permitirá que se dedique a ocupación o empleo alguno que pueda perjudicar su salud o educación o impedir su desarrollo físico, mental o moral.

\section{Artículo $10^{\circ}$}

El niño debe ser protegido contra las prácticas que puedan fomentar la discriminación racial, religiosa, o de cualquiera otra índole. Debe ser educado en un espíritu de comprensión, tolerancia, amistad entre los pueblos, paz y fraternidad universal, y con plena conciencia de que debe consagrar sus energías y aptitudes al servicio de sus semejantes.

La legislación internacional más reciente es la Convención sobre los Derechos del Niño. Fue adoptada por la Asamblea General de las Naciones Unidas el 20 de noviembre de 1989, así como firmada y ratificada en 1990 por un mayor número de países, entre los cuales, están los Estados Unidos Mexicanos. Los 54 artículos de dicha Convención plantean nuevos aportes jurídicos a los contenidos en la Declaración de los Derechos del Niño de 1959, entre los cuales está el reconocimiento pleno del niño como un sujeto de derecho, a partir de lo cual, todas las personas menores de 18 años tienen derecho a la protección, a desarrollarse y a participar activamente en la sociedad.

La Convención de los Derechos del Niño ha sido dada a conocer a través de la siguiente serie de derechos dirigidos a los mismos menores, los cuales son vigentes hasta la fecha:

A.- El derecho a la identidad, a conocer a tus padres y a ser protegido por ellos y por el gobierno.

B.- El derecho a expresar tus opiniones y estar informado de lo que te afecta.

C.- El derecho a recibir atención especial si sufres algún impedimento físico o mental.

D.- El derecho a tener una familia.

E.- El derecho a tener una vida segura y saludable.

F.- El derecho a la educación.

G.- El derecho a estar protegido contra la discriminación.

H.- El derecho a estar protegidos contra el abuso y el abandono.

I.- El derecho a la protección contra el trabajo perjudicial. 
Infancia y biopolítica en México contemporáneo. Del amparo de la ley al abandono.

\section{Bibliografía}

Agamben, G. (2004). Infancia e historia. Buenos Aires: Adriana Hidalgo.

— (2004). Estado de excepción: Homo sacer II. Valencia: Pre-textos. (2010). Homo sacer: El poder soberano y la vida nuda. Valencia: Pre-textos.

Arendt, H. (2005). La condición humana. Buenos Aires: Paidós.

Aulagnier, P. (1977). La violencia de la interpretación. Del pictograma al enunciado. Buenos Aires: Amorrortu.

Butler, J. (2002). Cuerpos que importan. Sobre los límites materiales y discursivos del "sexo". Argentina: Paidós.

Felman, S. (2012). El escándalo del cuerpo hablante. Don Juan con J. L. Austin o Seducción entre lenguas. México: Ortega y Ortiz.

Foucault, M. (2007). El nacimiento de la biopolítica. Buenos Aires: Fondo de cultura económica. (2002). Vigilar y castigar. Nacimiento de la prisión. Buenos Aires: Siglo XXI. (2002). Los anormales. Buenos Aires: Fondo de cultura económica.

Lacan, J. (1984). Seminario III: Las estructuras freudianas en las psicosis (1955-1956). Buenos Aires: Paidós.

— Seminario XXI: Real, Simbólico e Imaginario (1974-1975). Traducción del seminario oral en francés, por R. E. Rodríguez Ponte. Buenos Aires: Escuela Freudiana de Buenos Aires. (Versión no publicada).

— Seminario XXIII: El Síntoma (1975-1976). Texto establecido por Jacques-Alain Miller. Traducción del seminario oral, por Ricardo E. Rodríguez Ponte. Buenos Aires: Escuela Freudiana de Buenos Aires. (Versión no publicada).

— La familia (1978). Buenos Aires: Argonauta.

Martínez, S. (2009). Se venden niños. México: Temas de hoy.

Sotomayor, C. (2006). Los derechos de las niñas y los niños en México. Revista de la Escuela Libre de Puebla, núm. 3. Biblioteca Virtual del Instituto de Investigaciones Jurídicas de la UNAM (www.jurídicas.unam.mx).

Recibido: 31/10/13

Dictaminado: 09/01/14

Corregido: 07/02/14

Aceptado: 26/02/14 